\title{
La construcción dialógica del placer en el De vero bono de Lorenzo Valla
}

\author{
Mariano Vilar \\ Universidad de Buenos Aires \\ mvilar1984@gmail.com
}

Recepción: 19/07/2014, Aceptación: 08/10/2014, Publicación: 17/12/2014

\begin{abstract}
Resumen
El propósito de este artículo es analizar la estructura dialógica del De vero bono (también conocido como De voluptate y De vero falsoque bono, los títulos de su primera y segunda versión respectivamente) de Lorenzo Valla (c.1407-1457), con la intención de comprender cómo se construyen y representan en este texto distintas concepciones sobre el placer. Observaremos entonces los vínculos que presenta con la tradición pagana (con especial énfasis en el epicureísmo, escuela filosófica que estaba siendo reevaluada por los humanistas en el período en el que se compuso la obra) y cristiana, tanto en relación con la construcción formal del diálogo como con las posiciones en pugnas sobre el placer. Además, nos detendremos en la representación que aparece en el De vero bono de tres enfoques diferentes sobre el lenguaje: el retórico, el poético y el filosófico. Por último, analizaremos el uso de distintos recursos retóricos, en particular, el uso de los relatos.
\end{abstract}

Palabras clave

Lorenzo Valla; De vero bono; Diálogos; Renacimiento; Placer

\begin{abstract}
The dialogic construction of pleasure in Lorenzo Valla's De vero bono

The purpose of this article is to analyze the dialogic structure of the De vero bono (also known as De vero falsoque bono and De voluptate, the titles of its first and second version respectively) of Lorenzo Valla (c.1407-1457), with the objective of understanding how different conceptions of pleasure are represented in this text. We will observe the links with the pagan tradition (with special emphasis on Epicureanism, a philosophical school that was being re-evaluated by the humanists in the period in which the work was
\end{abstract}


composed) and with the Christian tradition, both in relation to the formal construction of the dialogue and to the debates about pleasure. In addition, we identify three different approaches to language in the De vero bono: rhetoric, poetic and philosophical. Finally, we discuss the use of various rhetorical devices, in particular, the use of narrative.

\section{Keywords}

Lorenzo Valla; De vero bono; Dialogue; Renaissance; Pleasure

\section{Introducción}

De vero bono es uno de los tres títulos con los que circuló el diálogo de Lorenzo Valla. La primera versión, de 1431, fue titulada De voluptate, y a lo largo de los siguientes veinte años, Valla alternará entre De vero bono (así es como se refiere a su propio texto en algunas de sus epístolas y en su Repastinatio) y De vero falsoque bono. ${ }^{1}$ Las distintas versiones implican sucesivas amplificaciones, y sobre todo, cambios en los personajes que forman parte del diálogo. Mientras que en la primera versión debaten Leonardo Bruni (representando la posición estoica, que privilegia la honestas), Antonio Beccadelli (defensor del placer y autoproclamado epicúreo y cirenaico) y Niccolò Niccoli (quien sostiene la defensa de la ética cristiana y del placer ultraterreno), en las redacciones posteriores estos tres interlocutores son reemplazados por Catón Sacco, Maffeo Vegio y Antonio da Rho (también conocido como «Raudense»), respectivamente. El resto de los personajes del diálogo, cuya participación es mucho menor, también experimenta modificaciones. ${ }^{2}$

Desde su primera circulación entre los humanistas contemporáneos, el diálogo de Valla provocó cierta incomodidad, debido mayormente a la apología del placer que aparece en los dos primeros libros. Leonardo Bruni, en una carta a Valla de 1433 en la que se refiere a la temática (res) y a la forma del libro (verba) por separado, elogia abiertamente a la segunda pero se cuida de opinar directa-

1. Para un análisis pormenorizado de las variaciones en el título y en el texto, ver la introducción a la edición crítica de Maristella Lorch (1970) citada en la bibliografía.

2. En las versiones posteriores a 1431, los personajes secundarios son Antonio Bernerio, Pier Candido Decembrio, Giovanni Marco, Antonio Bossio y Guarino Veronese. Para más detalles sobre la trayectoria de Valla al momento de escribir el De vero bono y sobre sus motivos para estos cambios, véase Fubini (1990: 346). 
mente sobre la primera $(2 \mathrm{~B}, 24){ }^{3}$ Algo similar refiere en otra epístola Ambrogio Traversari, quien elogia la libertad de Valla pero se abstiene de juzgar el contenido de la obra por haberla leído de forma apresurada $(2 \mathrm{~A}, 22)$. Poggio Bracciolini, quizás el principal antagonista de Valla durante su vida, utilizó secciones de este texto en sus invectivas contra Valla con el objetivo de acusarlo de libertino. ${ }^{4}$ En el siglo XvI predominan dos posturas: la de Pietro Aleandri, humanista veneciano, quien destaca el valor religioso del diálogo y considera que es una defensa valiosa de la doctrina cristiana, y la del impresor Josse Bade, quien consideró que los dos primeros libros (donde aparece la apología de la voluptas) son indignos de ser leídos por un cristiano, y que el mismo Epicuro los hubiera rechazado. ${ }^{5}$

La conexión entre la defensa del placer que aparece en los dos primeros libros del De vero bono y la revalorización del epicureísmo que tiene lugar a principios del siglo XV también ha sido objeto de debates en la crítica contemporánea. Aunque la aparición entre los siglos XIV y XV de una nueva perspectiva sobre el epicureísmo fue reconocida ya por Don Cameron Allen (1944) y Eugenio Garin (1961), su estudio ha recibido un impulso renovado en el siglo Xxi, en particular gracias a los textos de Gambino Longo (2004) Brown (2010) y Greenblatt (2012). Todos estos trabajos apoyan la hipótesis de que, dentro del movimiento general de recuperación y revalorización de la Antigüedad pagana que caracteriza al humanismo renacentista, aparece una nueva visión de Epicuro y de su escuela mucho más positiva de la que predominaba en la Edad Media. ${ }^{6}$ Mientras que en este último período era habitual que se vinculara a Epicuro con los placeres carnales y el ateísmo, estudiosos italianos del Quattrocento como Cosme Raimondi, Francisco Filelfo y Bartolomeo Scala se ocuparon de limpiar su imagen, especificando con más detalle el tipo de placeres y el tipo de vida por la que abogaba el filósofo del Jardín. Dos textos contribuyeron especialmente con esta nueva percepción: el De rerum natura de Lucrecio, redescubierto por Poggio Bracciolini en 1417, y la traducción íntegra al latín de las Vidas y opiniones de los filósofos más ilustres de Diógenes Laercio,

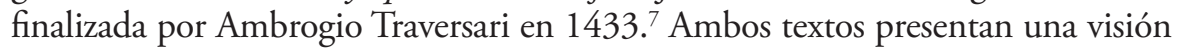
claramente positiva de Epicuro y su filosofía.

Sin embargo, incluso antes de que estos textos circularan abiertamente, la relectura de obras de Cicerón (en particular las Tusculanae, el De finibus y el De

3. Seguimos la numeración de las cartas de Valla de la edición bilingüe (latín-inglés) de Brendan Cook (2013) citada en la bibliografía final.

4. Mucho se ha escrito sobre esta disputa. Véase Camporeale (2001) para un resumen breve de sus principales temas.

5. Lorch (1977: 27-28) analiza y describe el posicionamiento de estas dos figuras respecto del texto de Valla.

6. De todos modos, cabe aclarar que la consideración medieval de Epicuro no estuvo exenta de complejidades. Véase al respecto Robert (2013).

7. Acerca del texto recuperado por Poggio, véase Flores (1980). Sobre la traducción de Traversari: Stinger (1977). 
natura deorum) junto con las epístolas morales y los tratados de Séneca, desde una perspectiva que buscaba de forma deliberada apartarse del punto de vista dominante en los textos medievales, posibilitó una revalorización de distintos aspectos del epicureísmo. ${ }^{8}$ Estos aspectos no estaban por lo general relacionados con la teoría atómica (inspirada en Demócrito), ni con la concepción epicúrea de la divinidad (que se oponía a la noción judeocristiana de la Providencia), sino en particular con la clasificación de los placeres y la reflexión sobre su lugar en el summum bonum del ser humano. Esta es precisamente la cuestión que aparecerá trabajada en el De vero bono. Aunque Poggio había redescubierto el texto de Lucrecio catorce años antes de la primera redacción de su texto, las probabilidades de que Valla conociera de primera mano el De rerum natura son prácticamente nulas. Niccolò Niccoli había retenido para sí el manuscrito, e incluso Poggio tuvo que esperar hasta 1430 para tener acceso a él. ${ }^{9}$ Es más difícil constatar si Valla conoció las traducciones de Traversari de Diógenes Laercio. A juzgar por el texto mismo del De vero bono, sin embargo, todo parece indicar que las únicas fuentes a las que tuvo acceso para dar forma a su elogio de la voluptas son secundarias. En particular, tomó elementos de los diálogos filosóficos de Cicerón, los tratados y las cartas morales de Séneca, y los escritos de Agustín y Lactancio, todos ellos disponibles ya en el Medioevo. ${ }^{10}$

Ya que aquí nos proponemos analizar la forma en la que se reflexiona y debate sobre el placer «epicúreo» en el De vero bono atendiendo en particular a su estructura dialógica, resulta conveniente recordar la importancia que tenía en su contexto histórico y cultural la imitación del modelo ciceroniano. ${ }^{11}$ Aunque presenta variaciones internas, este modelo tiene algunas características recurrentes. A diferencia de lo que suele suceder en los diálogos de Platón, en los textos de Cicerón los interlocutores disputan desde bases teóricas definidas desde un comienzo. ${ }^{12}$ A menudo se privilegian en los diálogos ciceronianos las exposiciones ininterrumpidas (oratio perpetua o continens) por oposición al método

8. Al respecto es particularmente útil el estudio de Gambino Longo (2004: 25).

9. Gambino Longo (2004: 27)

10. Di Napoli (1971: 195)

11. Sobre el predominio del modelo ciceroniano en el siglo xv, véase sobre todo Marsh (1980) y Rallo Gruss (1996).

12. Cox (1992: 12) marca esta división indicando que mientras el método socrático se basa en la mayéutica (Sócrates como partero), la auctoritas de los oradores ciceronianos los sitúa más bien como «abuelos» de la verdad. Cabe mencionar que estas diferencias no le impiden a Cicerón compararse con el modelo socrático en varias ocasiones. Por ejemplo, en las Tusculanae V, 4. declara su de intención disputar con el modo socrático de ocultar su propia opinión y liberar gradualmente a los otros de sus errores. Las Tusculanae se aproximan más a los diálogos de Platón que el De finibus y el De natura deorum, ya que aquí no se presenta a los interlocutores como pertenecientes a distintas escuelas. Pero a diferencia de lo que sucede en Platón, predominan los discursos largos, y la relación de maestro-discípulo está mucho más enfatizada entre los interlocutores. El maestro ya parte de un conocimiento estructurado sobre las cuestiones a trabajar. 
de refutación (elenchos) más característico de los textos platónicos que tienen a Sócrates como protagonista. Por último, la presencia de proemios explicativos y de personajes bien definidos en términos espacio-temporales son elementos preponderantes en la obra de Marco Tulio, y podemos hallarlos también en muchos textos contemporáneos a la obra de Valla que aquí nos ocupa.

\section{El modelo ciceroniano en el De vero bono}

En su proemio al De vero bono, Valla se apoya en Lactancio y San Agustín como guías que lo apoyan en su ataque a la filosofía pagana, pero al mismo tiempo declara que empleará estos elementos de acuerdo a un método "nuevo» (nova ratio). Desde nuestra perspectiva, algunas de estas novedades se vuelven más claras si se las considera en comparación con el De finibus bonorum et malorum de Cicerón. ${ }^{13}$ Veremos en este apartado algunas importantes similitudes y diferencias entre estos diálogos.

Ya el título de la versión con la que trabajamos, De vero bono, anuncia la filiación con el texto ciceroniano, que no era transparente en el título original (De voluptate). Las características centrales que hemos mencionado en nuestra breve descripción de los diálogos de Cicerón aparecen en el De vero bono. Podemos encontrar otra importante similitud ni bien nos adentramos en el $D e$ finibus. Tanto allí como en el De vero bono, se trata en primera instancia de aprovechar el otium y de la presencia de un hombre con auctoritas. Torcuato desea sacar ventaja de que Cicerón se encuentra ocioso para hablar de filosofía, así como los personajes del diálogo de Valla desean beneficiarse intelectualmente del ocio de Leonardo Bruni en la versión de 1431 y de Catón Sacco en las subsiguientes. En este texto, como es de esperar en el contexto del siglo Xv (siguiendo el modelo del propio Bruni en su Dialogi ad Petrum Paulum Histrum), la situación misma del diálogo es valorada como una práctica que remite a la "costumbre de los antiguos» (mos veterum). Estos dos elementos vuelven innecesaria la existencia de un interrogante concreto: Catón es libre para elegir el tema. En la situación que nos presenta Valla se destaca la oportunidad de llevar a la práctica un diálogo con hombres eruditos a la «manera antigua» por sobre la cuestión que se tratará.

13. Marsh (1980: 55) considera que la principal inspiración de Valla es el De natura deorum y no el De finibus, ya que en este último texto las posiciones de cada escuela filosófica son expuestas en jornadas separadas, mientras que en el De natura, como en el De vero bono, el debate se desarrolla en un mismo encuentro. Además, la postura de Valla queda ambiguamente planteada, mientras que el De finibus es más directo en su condena del epicureísmo. Por nuestra parte consideramos que estas diferencias no bastan para desplazar las similitudes temáticas y los cruces intertextuales en el tratamiento sobre la voluptas y la discusión sobre el summum bonum que dominan tanto el De finibus como el texto de Valla que estamos analizando. 
Sin embargo, dada la distancia entre el contexto de Valla y el de Cicerón, apenas hace falta decir que la reapropiación de estos elementos implica una serie de cambios. En una primera instancia, cabe preguntarse si la interrogación que dirige el recorrido del diálogo en el texto ciceroniano encuentra similitudes en el de Valla. Hemos visto que el diálogo parte del ocio en ambos casos, pero no encontramos una simetría equivalente en lo referente a los proemios de cada obra. En el De finibus, Cicerón se pregunta:

¿Cuál es el fin, cuál el extremo, cuál el bien definitivo al que deben ordenarse todos los principios de vivir bien y de obrar rectamente; qué es lo que la naturaleza persigue como el supremo de los bienes deseables y qué es lo que rechaza como el mayor de los males? (De finibus, I, 11) 14 $^{14}$

Además, el proemio declara que su objetivo consiste también en «hacer más doctos a sus conciudadanos» (I, 10), con lo que el debate posterior queda enmarcado en un movimiento didáctico. Debido a esto, inicia el diálogo presentando las tesis de Epicuro, por considerarla como la escuela más conocida entre los romanos. ${ }^{15}$

El proemio de Valla al De vero bono es considerablemente diferente. El asunto en cuestión aparece ya identificado en la primera frase del libro:

Cuando me propuse hablar acerca de la causa del verdadero y del falso bien tratada en los tres próximos libros, me pareció más oportuno seguir una división de acuerdo con nuestra creencia de que existen sólo dos bienes: uno en esta vida, el otro en la futura. Necesariamente deberemos referirnos a ambos, pero de un modo que parezca que nos hemos movido desde el primero al segundo gradualmente. ${ }^{16}$ (De vero bono, I, 1$)^{17}$

Este proemio contrasta con el que se encontraba en las primeras versiones del texto, en las que el asunto era identificado en primer lugar como la voluptas y posteriormente como bonum. ${ }^{18}$ Reparemos en un aspecto importante presente

14. Quid est enim in vita tanto opere quaerendum quam cum omnia in philosophia, tum id, quod his libris quaeritur, qui sit finis, quid extremum, quid ultimum, quo sint omnia bene vivendi recteque faciendi consilia referenda, quid sequatur natura ut summum ex rebus expetendis, quid fugiat ut extremum malorum? Las traducciones en español de Cicerón corresponden a la traducción de Herrero Llorente (1987) citada en la bibliografía final.

15. Esta no es la única razón: el intercambio final entre estoicos y peripatéticos mostrará que ambas escuelas tienen mucho en común en lo que se refiere a la ética.

16. Instituendi mihi de causa veri falsique boni dicere, de qua tribus hisce libris explicatur, placuit hanc potissimum sequi partitionem ut duo tantum bona esse credamus, alterum in hac vita, alterum in futura. De quorum utroque necessario nobis disserendum est sed ita ut ex priore ad sequens gradum quendam fecisse videamur.

17. Las citas del De vero bono fueron tomadas de la edición crítica de Maristella Lorch (1970) citada en la bibliografía. Las traducciones me pertenecen.

18. Véase Lorch (1977: 33) para un estudio pormenorizado de las variaciones en la introducción al De vero bono. 
en este párrafo introductorio: de entrada se trata de la división entre veri falsique boni, y luego se menciona a los bienes terrenales (in hac vita) y los ultraterrenos (in futura), sin que se explicite si hay una equivalencia exacta entre ambas divisiones. El proemio de Valla ubica la discusión en un contexto netamente cristiano, en el que la filosofía pagana aparece como una peligrosa vía hacia la umbra virtutis que debe ser atacada con sus propias armas. No hay aquí un propósito didáctico, sino más bien una fuerte intención polémica. ${ }^{19} \mathrm{Si}$ bien ambos recurren a la captatio benevolentiae, poco queda en Valla del tono amable con el que Cicerón se dirigía a su amigo Bruto.

Si observamos el comienzo del De finibus, la pregunta por los fines no está explícitamente formulada por los interlocutores. El movimiento que inicia la discusión surge de la interacción entre el epicúreo Torcuato y Cicerón (nos referimos ahora al Cicerón-personaje y no al Cicerón-narrador del proemio) y consiste en una mutua provocatio: como dijimos, Torcuato desea aprovechar el hecho de que Cicerón se encuentra otiosus para forzarlo a exponer los motivos por los que rechaza la escuela epicúrea. A esto responde Cicerón con una breve pero destructiva crítica al filósofo del Jardín, cuyo objetivo, según declara de forma explícita en el texto, no es otro que incitar a Torcuato a iniciar una defensa sistemática de sus doctrinas.

En el texto de Valla, la primera cuestión que se discute no es la voluptas, sino la relación entre Naturaleza y virtud. Es el epicúreo Vegio quien, luego de escuchar a su adversario, iniciará el debate central del De vero bono en el capítulo XIV del libro primero. Luego de desestimar la exposición de Catón y de considerarla digna de risa (I, viI), iniciará su defensa de la mater natura. Sólo cuando esta defensa haya finalizado aparecerá la cuestión del verdadero bien y Vegio planteará que se discutirá precisamente si se trata de la honestas o la voluptas. De todas maneras, Vegio explicita que su ataque contra los estoicos desde una perspectiva epicúrea es una forma de fingimiento, ya que ninguno de los participantes pertenece realmente a estas sectas. Su objetivo será modificar la presumpta opinio de Catón con argumentos y no con un despliegue de elocuencia.

Si nos remitimos ahora a la estructura general del texto de Valla, la mayor diferencia que se observa con el De finibus (y también con el De natura deorum) es que el epicúreo ya no es el primer orador, sino el segundo. Esta divergencia

19. Es posible comparar el proemio del De vero bono con la Peroratio con la que cierra el tercer y último libro de la Repastinatio. En ambos textos Valla utiliza la metáfora del «soldado cristiano» para justificar la violencia de sus embates, cuyo objetivo es simultáneamente la defensa de la Fe y de la verdad. La diferencia central estriba en que mientras las Disputationes polemizan contra la dialéctica tal como la entendían los filósofos cristianos de Boecio en adelante (siguiendo para esto una tradición), en el texto que aquí trabajamos los «enemigos» no son otros que los filósofos paganos, erróneamente sobrevalorados por algunos de los contemporáneos de Valla. Tal como sostiene Blanchard (2000: 154), Valla no se limitaba a criticar al establishment de la teología académica, sino que también cuestionaba continuamente a los humanistas de los que era contemporáneo. 
es fundamental para el propósito de Valla, quien ya había anunciado su deseo de avanzar ad sequens gradum hacia la verdad. En el proemio al libro II insiste asimismo en la importancia de presentar los argumentos en el orden apropiado. Antonio da Rho declara explícitamente en el libro tercero que la concepción epicúrea de la voluptas está más cerca de la cosmovisión cristiana que la estoica con su umbra virtutis, cuya supuesta autosuficiencia es una falsedad. Mientras que el modelo ciceroniano implicaba desterrar al epicureísmo lo antes posible para pasar al debate entre estoicos, académicos y peripatéticos, aquí es el estoicismo el blanco fácil de los ataques.

La inversión de posiciones del estoicismo y el epicureísmo, independientemente de que Valla presente bajo estos nombres teorías que apenas corresponden con las de estas sectas en el mundo antiguo,$^{20}$ tiene una gran importancia para la estructuración del diálogo. ${ }^{21} \mathrm{El}$ cristianismo primitivo sostuvo una fuerte polémica contra la escuela del Jardín, mientras que se mostró más benevolente con algunos aspectos de la concepción estoica de la moral. ${ }^{22}$ La honestas ocupaba, sin lugar a dudas, un lugar mucho más alto que la usualmente despreciada voluptas. En términos estructurales, por lo tanto, el rápido falseamiento de las tesis "estoicas» de Catón Sacco en los primeros capítulos del libro primero por contraposición a la larga exposición del epicureísmo que ocupa el resto de ese libro y la totalidad del segundo, tiene sin duda un efecto importante en la lectura del texto.

El otro aspecto macroestructural que no debemos perder de vista en la dinámica propia del De vero bono se relaciona con las normas implícitas del diálogo. Como dijimos, se trata en un principio de aprovechar el ocio y la erudición de Catón Sacco para revitalizar una costumbre de los antiguos. Nada se dice al respecto acerca del marco filosófico o doctrinal desde el cual se planteará la cuestión, pero tanto Catón como Vegio asumen que el horizonte conceptual de la discusión excluirá todo aquello relacionado con el cristianismo. En otras palabras, los dos primeros interlocutores discuten sobre temas como la provi-

20. No ahondaremos aquí en los numerosos aspectos en los que Catón se aparta del estoicismo tal como lo conocemos por las fuentes antiguas ni en las diferencias entre el hedonismo de Vegio y aquel que se le atribuye a Epicuro. En pocas palabras, puede destacarse en el primer caso la distancia entre la natura noverca de Catón y la providencia y la ley natural que los estoicos consideran como parte integral de su sistema, tal como lo expone Balbo en el De natura deorum ciceroniano (II 81). En relación con el epicureísmo, el concepto de ataraxia ligado a la ausencia total de dolor y de angustia en el cuerpo y el alma es netamente distinto de la exaltación por parte de Vegio de los placeres sensoriales. Véase al respecto Trinkaus (1995: 109-112) y también la epístola ya citada de Ambrogio Traversari $(2 \mathrm{~A}, 22)$ en la que le señala a Valla que se ha tomado varias libertades y licencias en relación con la obra de los filósofos antiguos.

21. Véase al respecto Fubini (1990: 372).

22. Antolín Sánchez (2003) ha dedicado recientemente un estudio revelador acerca de los puntos de conflicto entre cristianismo y epicureísmo en la Antigüedad tardía, donde sostiene que las tensiones surgían precisamente por aquellos elementos que poseen en común. También puede consultarse al respecto el texto ya citado de Stephen Greenblatt (2012). 
dencia, la virginidad, la relación entre el alma y el cuerpo, entre el ser humano y la naturaleza y (especialmente) entre la honestas y la voluptas, haciendo caso omiso de lo que al respecto se dice en la Biblia o en los textos de los doctores de la Iglesia. ${ }^{23}$ Sólo en el libro tercero, en el parlamento final a cargo de Antonio da Rho se señala explícitamente (y en términos de denuncia) esta ausencia en las intervenciones de sus interlocutores:

No obstante, Catón y Vegio, hubieran hecho mejor si hubiesen afirmado la doctrina de Dios en vez de la estoica y la epicúrea y no hubiesen preferido, por amor al ejercicio y la novedad, deleitarse en reproducir los temas de los antiguos y su forma de debatir. ${ }^{24}$ (De vero bono, III, vII, 106)

Es claro que esta intervención del Raudense, que introduce la sección cristiana de su discurso, señala un fuerte cambio en el horizonte de interrogaciones que manejaban hasta entonces los interlocutores. Ya no se tratará de una discusión basada en los modelos filosóficos existentes, sino en la reflexión sobre los dogmata. A continuación, Antonio identifica a Vegio y Catón como «defensores de la fe», que hablaron desde otros marcos conceptuales sólo para ejercitarse en la retórica. En adelante, ya no se tratará tanto de disputar sobre la res sino de explorar de forma poética las bondades de la voluptas cristiana.

Lorch (1991) interpreta el diálogo de Valla como un «drama teatral», cuyo primer acto estaría constituido por la primera confrontación entre la honestas, instituida por el estoico como problema, y la subsiguiente respuesta del epicúreo en defensa de la voluptas. El segundo acto (que se corresponde con el segundo libro) consiste en la reducción de todos los problemas tradicionales ligados a la ética a la confrontación entre la honestas y la voluptas, siempre favoreciendo a esta última. Finalmente, el tercer acto resuelve el conflicto dramático al revelar que la esencia de la voluptas es la caritas cristiana. Por nuestra parte, no coincidimos con muchos de los presupuestos que implican esta concepción del texto y preferimos analizarlo atendiendo a su estructura argumentativa. Vimos por ejemplo que es erróneo afirmar que el estoico introduce el tema, ya que es el epicúreo quien plantea la confrontación entre honestas y voluptas. Sin embargo, Lorch (1991: 111) señala acertadamente que en el De vero bono coexisten formas diferentes de usar

23. Esta forma de plantear las cuestiones no es original de Valla, y la encontramos también en otros diálogos humanistas, como el Diálogo a Pier Paolo Vergerio de Bruni, aunque cabe aclarar que los temas ahí tratados no tienen la impronta filosófica de los que aparecen en el De vero bono. Cabe señalar una intromisión significativa en el horizonte pagano de los dos primeros libros, de todas formas, cuya significación analizaremos en el capítulo siguiente de este trabajo: Vegio se refiere al De opificio dei de Lactancio aludiendo a la perfección del mundo natural (De vero bono, I, X, 74), pero sin hacer alusión a la divinidad.

24. Dii tamen melius quam ut illorum dogmata tu quidem, Cato, stoicum, tu autem, Vegi, epicureum velitis asserere et non potius ostenderitis vos vel exercitationis vel novitatis gratia delectatos in referenda priscorum hominum et materia et consuetudine disputandi. 
el lenguaje para la persuasión. Esta diferencia nos permite introducir un tema importante en relación con el modo en el que se enuncian los distintos segmentos de este diálogo. Los cambios en las interrogaciones que introducen variaciones en el horizonte de posibilidades de cada interlocutor se ven acompañados por estilos diferentes, y los mismos participantes del diálogo reflexionan al respecto. Dado que este tema excede en muchos aspectos la cuestión de la articulación de la voluptas, nos concentraremos en un aspecto vinculado a esa problemática en particular: la presentación retórica de la voluptas epicúrea (terrenal) y cristiana (celestial) y sus relaciones con el discurso poético y filosófico.

\section{Retórica del placer}

Luego del discurso de Antonio da Rho, Guarino Veronese es invitado a evaluar las intervenciones de cada uno de los oradores anteriores. Si bien el De finibus (al igual que el De natura deorum) finaliza con algunas observaciones elogiosas por parte de los interlocutores, no le dedica un gran desarrollo a esta sección. En el De natura deorum, de hecho, la cuestión queda abierta. El De finibus cierra — de forma en cierta medida análoga a lo que sucede en el De vero bono- remarcando los vínculos entre el sistema estoico y la academia, dejando de lado al epicureísmo. Guarino, en cambio, deja de lado el «estoicismo» de Catón y se refiere a los estilos oratorios de Vegio y Antonio de la siguiente forma:

Maffeo y Antonio deben ser comparados, cada uno conforme a la dulzura de su canto de alabanza al placer: Maffeo a la golondrina, Antonio al ruiseñor. ¿̨Por qué comparo estos hombres con estos pájaros? Ustedes saben que los poetas inventaron la historia de que estas aves eran hermanas, hijas del rey Pandión, pues su canto las hermana, y con esto significaron que la oratoria y la poesía son como hermanas. Y así como notaron esta similitud, notaron también la diferencia, puesto que uno de estos pájaros tiene una notable tendencia a habitar en los tejados de la ciudades, en tanto que el otro, en los arbustos y los bosques. Por esto, los poetas atribuían a la golondrina la elocuencia urbana que se ejercía entre paredes, en la curia y en los juicios, mientras que a Filomena (que llamamos ruiseñor) la elocuencia rural de los poetas, que buscan bosques y soledades y aman los lugares frecuentados por las Musas y no por los hombres. De esta forma, así como el canto del ruiseñor es superior al canto de la golondrina en armonía, volumen, dulzura y variedad, también los poetas deseaban que su propia voz fuera superior a la de los oradores o a la de cualquier otro. [...] Vegio, quien según pienso es comparado a un ruiseñor entre los poetas, esta vez, al contrario, me pareció más próximo a la golondrina, y el Raudense al ruiseñor. ${ }^{25}$ (De vero bono, III, XXviI, 137)

25. Mapheus et Antonius de laudibus voluptatis uterque pro se suavissime quasi cantare visi sunt, sed Mapheus hirundini, Antonius philomene magis comparandus. Cur hos viros potissimum istis avibus comparo? Scitis poetas finxisse has aves sorores fuisse, Pandionis regis filias, credo quod videbantur in cantando pene germane, et in his significasse oratoriam atque poeticam, que prope sorores sunt; atque ut hanc simili- 
Guarino alude en primer lugar a la historia de Procne y Filomela, relatada por Ovidio en Las metamorfosis (VI, 424-674), e interpreta a las dos hermanas transformadas como metáforas de la poesía y la retórica. Pero es posible rastrear otro subtexto que apunta mayormente a diferenciarlas entre sí: el Dialogus de oratoribus de Tácito $(12,1)$. Aunque es más conocido por su brillante análisis de los motivos de la decadencia de la oratoria en la Roma imperial, la primera parte del texto está destinada a discutir la vida y la actividad del poeta por oposición a la del orador profesional. Aparece aquí la misma contraposición que hemos visto en el fragmento citado: al poeta le corresponde la soledad del bosque (in nemora et lucos, id est in solitudinem), lejos del streptitus de los litigantes de la urbe.

Para interpretar correctamente esta distinción entre "poesía» y "retórica» es necesario revisar la forma en la que aparece representado el discurso poético en otros pasajes del De vero bono. En primer lugar, cuando Vegio afirma que iniciará la defensa de la voluptas sobre la honestas, es acusado por Catón de hablar "poéticamente»: credis te nunc poetice loqui, ubi non solum non vera sed ne verisimilia quidem sepe dicuntur? (De vero bono, I, XIII, 20). Los oradores del texto de Valla, siguiendo a Quintiliano (Institutio, X, v, 4) reconocen que los poetas pueden permitirse cosas que no serían admisibles en un discurso argumentativo, aunque no por eso - como veremos más adelante- rechazan el uso de fuentes poéticas en la retórica. Para defenderse del ataque de su adversario, Vegio no presenta una defensa del poetique loqui, sino que se concentra en la crítica del discurso filosófico encarnado en los estoicos, a quienes descalifica movidos por odiosa pervicacia.

A lo largo de todo el texto, estas tres formas discursivas (retórica, poesía y filosofía) aparecerán opuestas o entrelazadas, dependiendo de las circunstancias y del argumento que se intente defender o atacar. En la mayoría de las ocasiones, los discursos retórico y poético se presentarán como aliados, mientras que la filosofía sufrirá los embates más violentos. Cuando Guarino opone el estilo poético al oratorio en el fragmento de más arriba, el discurso filosófico de Catón queda directamente excluido de la comparación. En el relato de Procne y Filomela de las Metamorfosis aparece de hecho un tercer pájaro: la abubilla (epops) en la que es convertido el cruel Tereo, responsable del sufrimiento de las hermanas. Aunque no hay suficientes motivos como para considerar que Guarino está asociando por omisión a Catón con este ave (cuyo rostro, dice Ovidio, parece

\footnotetext{
tudinem ita illam discrepantiam notasse, quod in altera inest mira libido tecta et urbes incolendi, in altera vero arbusta et silvas, voluisseque hirundinem similem esse urbane eloquentie, que intra parietes, in curia, in subsellis exercetur, philomenam (quam lusciniam dicimus) eloquentie memorali et poetarum, qui silvas et solitudines consectantur et loca non ab hominibus celebrata sed a Musis amant. Ita quantum luscinia in cantando hirundini prestat vocalitate, vi, suavitate, varietate, tantum poete vocem ipsorum oratoribus ceterisque prestare voluerunt. (...) Vegius, qui semper mihi inter ceteros poetas quasi philomena quedam videtur, hoc tamen tempore ipse quidem hirundo. Raudensis vero philomena visus est. (DV, III, XXVII, 2-4)
} 
armado siempre la guerra), ${ }^{26}$ no hay duda de que la exclusión de su discurso de la evaluación final del diálogo muestra que su conclusión no consigue armonizar todas las perspectivas en juego (Marsh, 1980: 77).

Vegio es muy explícito en cuanto al estilo con el que elige defender su tesis. Buscando diferenciarse de la solemnidad de su antecesor (Catón), empieza por reírse (arridens) para marcar el contraste (De vero bono, I, vIII, 12). Lorch (1991: 107) advierte que la risa del epicúreo, así como su uso de la ironía, implica un contraste con la rigidez del estoico y una identificación del orador con la res misma, es decir, la voluptas. Este gesto nos recuerda la aclaración de Valla en el proemio, donde señalaba que una defensa del placer tiene que hacerse en un tono placentero. Vegio define cual será su forma de argumentar de la siguiente manera:

Pero no esperen de mí un discurso ornamentado. Si así lo hiciese, comparado con algún orador ilustre y espléndido, me opacaría como una estrella al encontrarse con los rayos del sol. Una sola cosa les pido: que comparemos asunto con asunto, causa con causa, y no elocuencia con elocuencia. ${ }^{27}$ (De vero bono, I, IX, 14)

Si bien podríamos interpretar esta declaración como una mera captatio benevolentiae, consideramos que se ajusta mayormente al planteo que realizará este orador tanto en el libro primero como en el segundo, y que se diferencia a simple vista de la propuesta del Raudense en el tercero. La argumentación de Vegio se basa en desmontar los argumentos contrarios a la visión de la voluptas-utilitas que se propone defender, para lo que continuamente resalta el carácter imaginario de la honestas. Su forma predominante de argumentación radica en el uso de la procatalepsis, es decir, en la introducción de objeciones potenciales dentro de su propia argumentación. En cierto sentido, esta forma de incluir la voz de un otro proyectado le da a su retórica un cierto carácter dialógico, aun cuando se extiende por largos capítulos sin ser interrumpido por sus interlocutores. En las Tusculanae (III, 56), Cicerón señala que hay dos formas de argumentar: o analizar la res en sí misma, o usar ejemplos tomados de hombres ilustres. En el libro I, Vegio emplea principalmente la primera estrategia, mientras que los ejemplos célebres dominan el libro II. Vegio finge dialogar con los personajes históricos, imitando un procedimiento frecuente en Plutarco. ${ }^{28}$ Quintiliano, la principal referencia de Valla en términos retóricos, recomendaba también el uso de ejemplos tomados de la historia para demostrar un argumento. Además, este autor reconocía que las fábulas poéticas podían usarse para persuadir, aunque su uso sea menos efectivo

26. nomen epops volucri, facies armata videtur (Ovidio, Metamorfosis, VI, 674)

27. Sed nulla, queso, ornamenta dicendi a me expectetis. Que si qua essent, cum tam illustri ac splendido oratore comparatus velut stella aliqua ad solis radios delitesco. Unum rogo ut rem cum re, causam cum causa, non eloquentiam cum eloquentia conferendam putetis.

28. Véase Delcourt y Derwa (1968: 122). 
que los ejemplos históricos (Institutio, V, XI, 17). ${ }^{29} \mathrm{El}$ análisis del relato de Giges y el de la virgen vestal en el «senado platónico» nos serán de utilidad para describir la concepción del placer que aparece defendida por el personaje de Maffeo Vegio en los dos primeros libros del De vero bono.

El uso de la fábula de Giges por parte de Vegio ilustra su deseo de ir más allá de la noción filosófica convencional de la justicia. Recordemos que esta historia, narrada por Glaucón en el libro II de la República de Platón, tenía originalmente la función de ilustrar la pregunta acerca de si los hombres son justos porque desean serlo, o sólo porque temen el castigo que se les impondrá sin son descubiertos cometiendo una injusticia. Giges, cuyo anillo le permitía hacerse invisible y por lo tanto cometer actos inmorales sin riesgo alguno, sirve de ejemplo para este dilema. Cicerón retoma brevemente la historia en el libro III de su De officiis con el propósito de mostrar los peligros de desvincular la honestas de la utilitas. Cicerón, además, incluye una breve reflexión señalando que no importa si la fábula es inverosímil para captar su utilidad y significado. Le asigna una función heurística: podemos preguntarle a alguien qué haría en el caso de encontrarse con el anillo de Giges para saber si se trata o no de un hombre honesto (De officiis, III, 39).

Valla declara explícitamente estar tomando la historia de Cicerón, lo que no resulta sorprendente si tomamos en cuenta que la vinculación que propone Vegio entre voluptas y la utilitas debate con el De officiis. En primer lugar, hace caso omiso de la advertencia ciceroniana y se explaya sobre el aspecto inverosímil de la fábula, cuius fictio non quadrat nec sibi constat (De vero bono, II, XxvI, 71), con el objetivo de mostrar que el ejemplo carece de toda coherencia. Valla utiliza argumentos similares para cuestionar la verosimilitud de la historia de la donación de Constantino. ${ }^{30} \mathrm{La}$ interpelación a la filosofía y a la historia desde el sentido común es una de las constantes que recorren su obra. La retórica, por su conexión con el lenguaje en uso, es mucho más efectiva para plantearse un problema sin caer en abstracciones vacías. En este sentido, la inconsistencia de la fábula de Giges afecta negativamente a su efectividad como mecanismo retórico persuasivo.

Sin embargo, el aspecto más llamativo de la utilización de Vegio de esta fábula radica en las conclusiones que extrae de ella. En primer lugar, considera que el único error de Giges fue cambiar una vida feliz de campesino por una de Rey, llena de inquietudes. Anteriormente en el texto (I, II), Catón y Vegio habían disputado sobre un pasaje de las Georgicas de Virgilio, y Vegio había demostrado que la vida del campesino está guiada por la voluptas. Más llamativamente aún, Vegio considera que la violación de la reina por parte de Giges es un acto loable

29. En su Repastinatio (III, 15), Valla incorpora varios capítulos de la Institutio de Quintiliano, entre los que se encuentran aquellos referidos al uso de ejemplos históricos o ficticios.

30. Para un análisis del modo en que Valla utiliza el «sentido común» como una de sus principales estrategias argumentativas, véase Lodi Nauta (2009). 
que debería ser imitado por cualquier hombre en su posición, al menos si la reina es bella y joven. Ningún legislador se opondría a un adulterio como el que posibilitaría el anillo de Giges. La reina, dice también, se regocijará (gaudebit). Junto con el discurso de las vírgenes vestales que analizaremos a continuación, este fragmento figura entre los más «libertinos" y sorprendentes del diálogo de Valla. ${ }^{31}$

La crítica de la virginidad impuesta a las mujeres que lleva a cabo Vegio en la última parte del libro primero (I, XXVI-XLIX) es un interesante ejemplo del uso de la ficción y de la retórica deliberativa para sostener la causa de la voluptas. Vegio adopta el lugar de la mujer en un imaginario senado platónico y enuncia una serie de argumentos para sostener que la relación entre sexualidad y feminidad posee una intensidad natural que no debe ser sometida a una regulación tan estricta (I, XLIII). Reaparecen aquí las Metamorfosis con el mito de Tiresias y la disputa entre Zeus y Hera acerca de a qué sexo le correspondía mayor goce. También aquí, como en Giges, la influencia de la República es evidente, dado que es precisamente en ese texto en donde se defiende la tesis de que las mujeres deben ser propiedad común, como Vegio se ocupa de señalar antes de dar inicio al discurso ficticio de la mujer. La ley de la República platónica que descarta el adulterio es la ley natural, dice explícitamente, mientras que la ley Julia es arbitraria (Quid Platonem dico? Immo nature. Illa lex iulia scripta est, hec nata-De vero bono, I, XL, 36). Vegio instaura una ficción que remeda las intervenciones frente al senado de los oradores de la Antigüedad, utilizando una estructura argumentativa coherente con el resto del discurso del epicúreo. Esta es la sección más polémica del texto de Valla, y su persistencia en la última versión demuestra que no estaba dispuesto a eliminarla pese a los peligros de la censura. No deja de ser importante recordar que Vegio, para referirse a las vírgenes, habla de las vestales. Hasta que tome la palabra Antonio da Rho, el cristianismo está deliberadamente excluido de la discusión.

La justificación de estos excesos hedonísticos en el contexto del diálogo aparece enunciada por Antonio da Rho en su caracterización del ethos de Vegio, a quien compara con Sócrates: "Pues sospecho que no lo hiciste en serio sino a modo de juego, según tu hábito, a la manera de Sócrates, que los griegos llamaban ironía." ${ }^{32}$ (De vero bono, III, vII, 106). De esta forma, el discurso epicúreo no puede ser tomado literalmente, y en cierta medida se vuelve a lo que decía Catón desde un principio: la defensa de la voluptas sólo puede hacerse a modo de juego. No es exactamente esto lo que enuncia Antonio da Rho: el motivo por el que su discurso debe ser leído en clave irónica es que Vegio no es en realidad un adorador de la voluptas terrenal que cree en la mortalidad del alma humana,

31. En muchos sentidos, esto es análogo a lo que declara sobre la violación de Lucrecia en II, IV. También en este caso Vegio señala que el adulterio no debería ser motivo de escándalo.

32. Proinde suspicor non serio te fecisse sed ioco, que tua consetudo est, more Socratis quem eírona greci appellabant. 
sino un cristiano ferviente y estudioso. Valla habría elegido a Vegio precisamente para generar esta distancia, en la medida en la que Beccadelli (el defensor del epicureísmo en la versión de 1431) podría haber sido identificado como un auténtico predicador del epicureísmo, lo que comprometería cualquier posibilidad de establecer vínculos entre las dos formas de voluptas. ${ }^{33}$

Estos cambios en la dinámica del diálogo parecen indicar el fin de la discusión crítica que orientaba los dos primeros libros. Al señalar de forma enfática que ni Catón ni Vegio son estoicos o epicúreos (algo que ya había anticipado Vegio al iniciar su discurso), el Raudense aísla cuidadosamente las «creencias» de los personajes de sus «compromisos». La separación entre estos dos elementos (beliefs y commitments) ha sido señalada por Walton (2007: 23) con el propósito de identificar los compromisos que cada interlocutor asume a lo largo de su intervención en la situación discursiva con independencia de las creencias que puedan sostener fuera de ese contexto. Mientras que Catón se había comprometido con la tesis estoica de la honestas como summum bonum y Vegio con la voluptas, sus creencias nunca estuvieron realmente allí. El Raudense nos revela entonces que tras la discusión no había más que un grupo de cristianos eruditos y firmemente creyentes. En lo que queda del texto ya no se tratará de rebatir a los oradores sino a las ideas mismas, es decir, a la filosofía pagana como forma de pensar el horizonte ético del hombre.

Esto se realiza a partir de dos movimientos. El primero (capítulos IV a XV del libro tercero) refuta la teoría aristotélica del «justo medio» a la que había apelado Catón para afirmar que los vicios son más numerosos que las virtudes y presenta una defensa de la caritas cristiana como verdadera forma de virtud y de placer. En la segunda (a partir del capítulo XvI), aparece la descripción de la voluptas celestial, en la que nos concentraremos ahora. En el proemio al libro primero, Valla anticipa esta sección anunciando que la defensa de su tesis implicará un "cuasi-panegírico» del cielo. Notamos ya aquí una diferencia con el estilo argumentativo del epicúreo, más ligado a la retórica forense (defender la causa de la voluptas) y a la deliberativa (tal como aparece representada en el debate sobre la virginidad), es decir, a los otros dos géneros tradicionales de la retórica.

En su Institutio, Quintiliano señala que en la teoría retórica clásica los hombres que se reúnen para escuchar un panegírico buscan únicamente ser deleitados (ad delectationem conveniat). La persuasión ocupa un lugar secundario. De todas formas, Quintiliano considera también que el panegírico no está necesariamente apartado de la retórica deliberativa o forense, en la medida en la que puede incluir demostraciones para darle verosimilitud al asunto que se desea elogiar

33. En su Antidotum contra Fazio, Lorenzo Valla declara que en sus diálogos lo importante no es tanto quién enuncia cada idea, sino las ideas en sí mismas: Neque enim historiam, sed dialogum scribis, ubi pro nostro arbitratu sermonen cui volumus attribuimus, ubi non orationem persone, sed personam orationi accommodamus, ubi nibil admodum refert quis, sed quid loquatur (II, IX, 11). 
(Institutio III, viI, 4). Uno de los aspectos que destaca en este mismo capítulo para apuntalar su efectividad es tener en cuenta la naturaleza de los oyentes. Precisamente, Antonio da Rho introduce su elogio de la voluptas celestial haciendo alusión a sus interlocutores. Dado que se trata de hombres sabios y bondadosos, declara innecesario hacer una descripción de los sufrimientos infernales:

Las almas generosas no temen a las leyes, ni se alejan por el miedo de los castigos: al contrario, son atraídos por las recompensas. Deberé hablar ahora de acuerdo con mi plan sobre estos premios que consisten en el placer [voluptas] eterno y demostraré cuánto supera este placer eterno al terrenal. Escuchen pues un discurso sobre los premios de los cristianos en el que yo intentaréno repetir lo que es conocido y trillado sino decir algo nuevo. ${ }^{34}$ (De vero bono, III, XVI, 118)

Es continua en Valla la preocupación por la novedad (nova dicere), que ya encontrábamos en el proemio del libro primero. Cuando sus personajes principales explicitan sus intenciones, la preocupación por la oratoria y por la organización retórica de los argumentos ocupa un lugar más destacado que sus tesis filosóficas. Antonio da Rho no desea afirmar que presentará una visión del paraíso diferente de la del dogma, sino que la presentará de una forma novedosa. Recordemos que, para Valla, la fuerza del cristianismo está en su capacidad persuasiva. ${ }^{35}$

La descripción de la vida ultraterrena del Raudense puede dividirse en dos partes si atendemos a sus recursos argumentativos. La primera es la descripción misma de la salida del alma del cuerpo y de su llegada a la Jerusalén celestial, donde es recibida por las personas que murieron anteriormente (familiares y amigos, por ejemplo), los ángeles, los santos y profetas, la Virgen María, y por último, Dios mismo. La segunda parte, que está inserta dentro de la primera como un "desvío» (III, XXIv), sigue un modelo argumentativo bastante más cercano al que vimos en relación con el discurso de Vegio, en la medida en que utiliza la procatalepsis: se presenta la tesis de quienes niegan que debamos privilegiar los placeres del cielo porque nos son enteramente desconocidos, para luego refutarla. Sin embargo, el Raudense no defiende su concepción de la voluptas aludiendo a historias de la antigüedad pagana o al sentido común al que apelaba el epicúreo. Mientras que el ascenso glorioso del alma del mundo terrenal hacia Dios está dirigido a los hombres ilustrados que participan del diálogo, el capítulo XXIV del libro tercero se propone como una respuesta a objeciones que podrían realizar hombres menos formados, tanto en el nivel intelectual como en la fe.

34. Non extimescunt generosi animi leges, non suppliciis propositis deterrentur, sed premiis invitantur. De quibus premiis, que in eterna voluptate consistunt, ex instituto meo dicendum est et ostendendum quanto plus voluptas eterna terrene antecellat. Accipite ergo sermonem de premiis christianorum in quo ego non trita et pervulgata sed nova dicere conabor.

35. En esto coinciden Di Napoli (1971: 241) y Fubini (1990: 383). 
No es nuestro objetivo presentar aquí una descripción exhaustiva de los recursos y las figuras retóricas utilizadas por el Raudense. A grandes rasgos, podemos decir que sigue el modelo que propone Quintiliano para movilizar al público mediante visiones, es decir phantasiai (VI, II, 29). No es casual que Quintiliano hable también de voluptas para referirse al efecto que tiene sobre el público un panegírico perfectamente ornamentado (Institutio, VIII, III, 4). El procedimiento principal en punto a describir el cielo consiste en comparar alguno de los sucesos que allí tienen lugar (por ejemplo, el alma recibida por los ángeles y los otros habitantes del paraíso) con sucesos terrenales (por ejemplo, la recepción de un comandante que retorna a su ciudad luego de un triunfo militar), para luego afirmar que la diferencia cualitativa es inconmensurable y que las palabras apenas pueden empezar a aprehenderla. ${ }^{36}$ En el proceso aparecen entremezcladas la suavitas (término habitualmente asociado a la contemplación espiritual) con el gaudium, la delectatio y la voluptas. Pese a que declara que su inspiración es el Apocalipsis de Juan, el Raudense indica también que la visión que él intenta presentar no es necesariamente la única posible: "Cualquiera que lo desee puede imaginar esta ciudad conforme a su voluntad ${ }^{37}$ (De vero bono, III, xxv, 130-131).

La reacción de los interlocutores de Antonio da Rho frente a esta plétora de imágenes de gloria, redención, gaudium, voluptas y suavitas aparece dominada por una ingens admiratio, y Bernerio afirma que estaban todos tan ensimismados en sus palabras que no hubieran percibido la llegada de la noche de no ser porque el Raudense mismo lo señaló al finalizar. De todas formas, la presentación de la voluptas celestial no está exenta de contradicciones. Antonio señala que el auténtico cristiano confía plenamente en su creador y que, gracias a la esperanza y a la fe, no necesita ver cómo será la vida del bienaventurado para asegurarse de su existencia. Al mismo tiempo, afirma que es válido intentar alcanzar con la imaginación algunas de sus características, en la medida en que ayuda a stultos y sabios por igual a valorar la auténtica voluptas y a desplazar el cuerpo y las glorias terrenales del centro de nuestras preocupaciones.

A modo de epílogo, luego de la evaluación de Guarino, Vegio se ofrece a acompañar a Antonio de vuelta a su hogar con una pequeña comitiva de músicos, siguiendo la costumbre de Cayo Duilio, un romano del siglo III a.C. La negativa del Raudense puede ser interpretada como una prueba de las tensiones que permanecen abiertas tras la supuesta resolución del diálogo, ya que Catón fue excluido de la comparación de Guarino y Vegio muestra que incluso luego de reconocerse vencido por la poética cristiana de su adversario, sigue hablando

36. El Raudense sigue en esto una larga tradición medieval que explicaba con este y otros argumentos la incapacidad de describir propiamente la vida ultraterrena o incluso de imaginarla (Muessig y Putter, 2007).

37. Huic urbi affingere arbitrio suo qui vult potest. 
y actuando dentro del horizonte epicúreo-pagano de la voluptas terrenal..$^{38}$ Aunque esta interpretación es sugestiva y responde efectivamente a la sensación de que los esfuerzos poéticos del Raudense no bastaron para aplacar por completo el efecto de la apología de los placeres mundanos de Vegio, no deja de ser cierto que en el texto de Valla todos los interlocutores reconocen por unanimidad el triunfo del orador cristiano y la resolución efectiva de la cuestión del summum bonum, entendido en los términos ultraterrenos de la beatitudo cristiana. Por este motivo, su cierre no es comparable al de diálogos como el De natura deorum ciceroniano, donde se expresa clara y llanamente que los interlocutores sostienen opiniones distintas a la finalización del debate.

\section{Conclusiones}

Las diferencias centrales en el uso de recursos oratorios por parte de Vegio y del Raudense emergen del paso de un discurso apoyado en la argumentación forense y deliberativa, destinado a convencer mediante la refutación sistemática de las tesis contrarias y con abundante uso de ejemplos (ficcionales e históricos), a un panegírico que propone una descripción detallada y sensorial de aquella voluptas ultraterrena en la que consiste la vida eterna de los bienaventurados, apelando para ello principalmente a la imaginación y a la contemplación con los ojos del alma. La diferencia enunciada por Guarino entre un enfoque «retórico» y otro "poético» no debería confundirnos, ya que no se trata de afirmar que el discurso de Antonio da Rho esté pensado sólo para la ostentación o el placer, sino que es en sí mismo una forma de demostrar un argumento. Podemos concluir, observando la estructura general de la argumentación en el De vero bono, que la distinción realizada entre retórica y poesía es en última instancia menos relevante que aquellos aspectos que las emparentan. Recordemos que en el fragmento citado se comienza hablando de ambas modalidades enfatizando su hermandad (cantando pene germane [...] sorores sunt). Ambos oradores utilizan la narratio, que ya era reconocida por Aristóteles (bajo el nombre de diégesis) como un recurso válido en los tres géneros, aunque con diferencias específicas (Retórica, III, $\mathrm{xvI}$ ). La principal diferencia consiste en que el uso de la narratio por parte de Vegio se refiere a la reinterpretación de elementos de la cultura pagana (el mito de Giges, la República de Platón) en clave polémica, con el propósito de argumentar su causa demostrando su validez en todos los planos (históricos, míticos, ficcionales). En cambio, el relato del ascenso del alma del Raudense implica un nivel mucho mayor de involucramiento con sus interlocutores, en la medida en que se proyecta en su horizonte de expectativas como cristianos. ${ }^{39}$

38. Véase Marsh (1980: 76) para un desarrollo de esta perspectiva.

39. Compartimos en este aspecto algunos elementos de la tesis de Lorch (1985), aunque preferimos no adoptar el lenguaje que utiliza para describir el uso de las fuentes bíblicas por parte 
Todos los elementos formales y argumentativos que hemos analizado tienen consecuencias significativas en la articulación de la voluptas. La preeminencia del discurso epicúreo sobre el estoico invierte la estrategia ciceroniana y establece un espacio discursivo en el que las críticas al placer se contradicen a sí mismas y se construyen sobre un gesto solemne, ampuloso y risible. La separación que se postula entre el horizonte pagano de la primera parte de la discusión y la irrupción del dogma cristiano estratégicamente ubicada a la mitad del discurso de Antonio da Rho permiten que durante gran parte del texto la apología de la voluptas-utilitas terrenal pueda desarrollarse en total libertad. Los argumentos en contra de la concepción estoica, platónica y aristotélica (o lo que entendía Vegio por esos nombres) se basan en la experiencia mundana y en la razón práctica inspirada en la naturaleza. La diferenciación relativa de estilos argumentativos vinculada con la voluptas epicúrea implica un movimiento doble, que como su contrapartida cristiana, no está exenta de tensiones. En la medida en que Vegio habla como un orador civil (una figura altamente valorada por los humanistas de principios del xv), emplea argumentos racionales y convincentes desde la retórica para demostrar su caso utilizando relativamente poca ornamentación, al menos en comparación con sus adversarios. Pero simultáneamente, como lo demuestra de forma clara la ficcionalización del alegato femenino en el senado, está involucrado en una dinámica del fingimiento que no permite establecer con claridad un marco enunciativo. Esto se refuerza al poner en tensión los compromisos que asume con las creencias que le atribuyen los otros personajes luego de finalizar su alegato. La voluptas terrenal parece entonces sólo ser defendible dentro de la lógica del juego "poético» (en el sentido de «licencia poética»), como sostenía Catón cuando Vegio inicia su alegato.

No es posible decir, sin embargo, que la voluptas celestial aparezca, por oposición, libre de ambigüedades. La asociación con la poesía realizada por Guarino, y el carácter indudablemente imaginativo de la experiencia celestial que presenta el Raudense nos presentan otros modos de ficcionalización cuya naturaleza argumentativa no responde con exactitud a las demandas de Vegio de apelar a la experiencia humana. ¿Hasta qué punto la capacidad del orador cristiano por deleitar a sus oyentes con la voluptas celestial anula la apología de la voluptas terrenal de Vegio? Notemos al pasar que esto no sucede en la sección del discurso del Raudense que no estamos analizando (por no referirse centralmente a la cuestión del placer), en la que debate de forma racional y sin apelar a los dogmata dii contra la concepción aristotélica de las virtudes. Es la cuestión de la duplex

del Raudense como una forma de superación de la poesía virgiliana. Según esta autora, el texto bíblico permitiría un mayor acercamiento a la «esencia de la voluptas» en la medida en que supera las fronteras de la muerte que limitan al epicúreo. 
voluptas $^{40}$ (terrenal y ultraterrena) la que hace emerger esta tensión irresuelta en los distintos modos de argumentar.

Valla sin duda se sentía más cerca de la figura del orator que de la del poeta. En el De oratore (texto citado por Valla en diversas ocasiones a lo largo del De vero bono), Cicerón señalaba que est enim finitimus oratori poeta, aunque en última instancia el orador es superior por la magnitud de los conocimientos que exige su disciplina (De oratore, I, 70). Quintiliano, en una metáfora que Valla retoma en varios de sus textos, define al orator como un soldado: nos vero armatos stare in acie (Institutio X, I, 29). El uso de elementos poéticos, usados con ciertas precauciones, forma parte de su arsenal argumentativo. La relación con el discurso filosófico, como vimos, suele ser de confrontación. Es interesante advertir sin embargo que Vegio, poco antes de cederle la palabra al Raudense, plantea una objeción al uso de la ficción poética en relación con la vida ultraterrena. Apela para esto de nuevo a Cicerón, orador y filósofo, que en las Tusculanae (I, 10) se burla de la representación poético-mitológica del infierno, poblado por criaturas sobrenaturales, y sostiene que los esfuerzos de los filósofos (entre ellos, Epicuro) por demostrar la falsedad de todas estas fabulaciones son innecesarios (De vero bono, II, xxx, 85). No es este el único aspecto en el cual Vegio parece anticiparse críticamente a los argumentos cristianos del Raudense. Aunque resultaría excesivo interpretar que la atribución de un valor poético a este último por parte de Guarino es una forma sutil de desprestigiar la veracidad de su discurso (en la medida en que finalmente sería el cristiano quien habla poetice, y no, como sostenía Catón, el epicúreo), no deja de resultar importante, para comprender el diálogo en su totalidad, observar como los diferentes posicionamientos de los enunciadores y sus discursos minan las posibilidades de cerrar de forma definitiva su interpretación. Desde nuestra perspectiva, esto se debe a que más allá de la articulación entre una voluptas terrenal y otra celestial, el texto de Valla hace aparecer continuamente una voluptas anclada en la retórica, cuyo fundamento principal es el juego con los discursos. Si el panegírico del Raudense triunfa, es principalmente porque produce un mayor placer, al logar articular poética y retórica de una forma tan innovadora como efectiva.

40. La expresión duplex voluptas aparece enunciada por Antonio da Rho en el libro III (X, 110) con el propósito de distinguir entre el placer que podemos obtener en el presente (es decir, en la vida terrenal) y aquel al que podemos aspirar en el futuro (es decir, en el cielo). 


\section{Bibliografía}

Allen, Don Cameron, «The Rehabilitation of Epicurus and His Theory of Pleasure in the Early Renaissance», Studies in Philology, 41 (1944) 1-15.

Antolín SÁnchez, Javier, El epicureísmo en el cristianismo primitivo, Valladolid, Secretariado de Publicaciones e Intercambio Editorial, Universidad de Valladolid, 2003.

Brown, Alison, The Return of Lucretius to Renaissance Florence, Cambridge, Harvard University Press, 2010.

Camporeale, Salvatore, «Poggio Bracciolini Contre Lorenzo Valla. Les « Orationes in Laurentium Vallam ", Penser entre les lignes. Philologie et Philosophie au Quattrocento, Mariani-Zini Fosca, Lille, Presses Universitaires du Septentrion, 2001, 251-273.

Cicerón, Marco Tulio, Del supremo bien y del supremo mal, Víctor Herrero Llorente, Madrid, Gredos, 1987.

Cox, Virgina, The Renaissance Dialogue: Literary dialogue in its social and political contexts, Castiglione to Galileo, Cambridge, Cambridge University Press, 1992.

Delcourt, Marie, y Marcelle Derwa, "Trois aspects humanistes de l'epicurisme chrétien», Colloquium Erasmianum, Marcel Bataillon y Charles Bené, Mons, Centre Universitarie de l'État, 1968, 119-133.

Di Napoli, Giovanni, Lorenzo Valla: filosofia e religione nell'umanesimo italiano, Roma, Edizioni di Storia e Letteratura, 1971.

Flores, Enrico, Le scoperte di Poggio e il testo di Lucrezio, Nápoles: Liguori Editore, 1980.

Fubini, Ricardo, Umanesimo e secolarizzazione, Roma, Bulzoni Editore, 1990.

Gambino-Longo, Susanna, Savoir de la Nature et Poésie des Choses. Lucrèce et Épicure à la Renaissance italienne, París, Honoré Champion, 2004.

GaRIN, Eugenio, La cultura filosofica del Rinascimento italiano: Ricerche e documenti, Florencia, Sansoni, 1961.

Greenblatt, Stephen, El giro. De cómo un manuscrito olvidado contribuyó a crear el mundo moderno, Barcelona, Crítica, 2012.

LorCH, Maristella, "Voluptas, molle quoddam et non invidiosum nomen: Lorenzo Valla's Defense of Voluptas in the Preface to his De Voluptate», Philosophy and Humanism: Renaissance Essays in Honor of Paul Oskar Kristelle, Edward Mahoney, New York, Columbia University Press, 1976, 214-228.

—, «Introduction», On Pleasure / De voluptate, Lorenzo Valla, New York, Abaris Books, 1977.

—, A Defense of Life. Lorenzo Valla's Theory of Pleasure, Munich, W. Fink Verlag, 1985.

—, «The Epicurean in Lorenzo Valla's On Pleasure», Atoms, Pneuma, and Tranquility, Margaret J. Osler, New York, Cambridge University Press, 1991, 89-114. 
Marsh, David, The Quattrocento Dialogue, Cambridge, Harvard University Press, 1980.

Muessig, Caroly y Ad Putter (eds), Envisaging Heaven in the Middle Ages, Londres, Routledge, 2007.

Nauta, Lodi, In Defense of Common Sense. Lorenzo Valla's Humanist Critique of Scholastic Philosophy, Cambridge, Harvard University Press, 2009.

Rallo Gruss, Asunción, La escritura dialéctica: estudios sobre el diálogo renacentista, Málaga, Universidad de Málaga, 1996.

Robert, Aurélien, «Epicure et les Épicuriens au Moyen Âge», Micrologus, XXI (2013) 3-46.

Stinger, Charles, Humanism and the Church Fathers: Ambrogio Traversari (1386-1439) and the Revival of Patristic Theology in the Early Italian Renaissance, Albany, State University of New York Press, 1977.

Trinkaus, Charles, In Our Image and Likeness. Notre Dame, University of Notre Dame, 1995.

VAlla, Lorenzo, Correspondence, Cambridge, Harvard University Press, 2013.

—, De vero falsoque bono, Maristella Lorch, Bari, Adriatica, 1970.

Walton, Douglas, Dialog Theory for Critical Argumentation, Filadelfia, John Benjamins Publishing Company, 2007. 